\title{
Poeira x Unicon: diferentes discursos ${ }^{1}$
}

\author{
Poeira x Unicon: diferentes discursos \\ Poeira x Unicon: different discourses
}

Ms. Milena Costa Mascarenhas ${ }^{2}$

\begin{abstract}
Resumo
Neste trabalho foram analisados dois periódicos produzidos por sujeitos que participaram de diferentes maneiras do processo que envolveu a construção da usina de Itaipu. O Boletim Poeira e o Informativo Unicon foram pesquisados com o objetivo de expor as contradições deste empreendimento construído com base em muitos conflitos. Os dois instrumentos de organização foram pensados não só para noticiar o que acontecia, mas também educar e organizar seus leitores diante da construção da hidrelétrica binacional.
\end{abstract}

Palavras-Chave: Boletim Poeira; discursos; expropriados; Informativo Unicon; Itaipu Binacional.

\section{Resumen}

En este trabajo se analizaron dos periódicos producidos por sujetos que participaron de diferentes maneras del proceso que involucró la construcción de la usina de Itaipú. El Boletín Poeira y el Informativo Unicon fueron investigados con el objetivo de exponer las contradicciones de este emprendimiento construido sobre la base de muchos conflictos. Los dos instrumentos de organización fueron pensados no sólo para noticiar lo que ocurría, sino también educar y organizar a sus lectores ante la construcción de la hidroeléctrica binacional.

Palabras claves: Boletim Poeira; discursos; expropriado; Informativo Unicon; Itaipu Binacional.

\begin{abstract}
In this paper, two newspapers produced by subjects that participated in different ways of the process that involved the construction of the Itaipu plant were analyzed. The Boletim Poeira and Informativo Unicon were researched with the objective of exposing the contradictions of this enterprise built on the basis of many conflicts. The two instruments of organization were designed not only to report what was happening, but also to educate and organize their readers before the construction of the binational hydroelectric power station.
\end{abstract}

Keywords: Boletim Poeira; discourses; expropriated; Informativo Unicon; Itaipu Binational.

\section{Introdução}

Durante o processo de construção da usina hidrelétrica da Itaipu Binacional foram produzidos dois periódicos com objetivos e público-alvo diferentes, porém ambos voltados a uma mesma questão: a temática principal girou em torno da Itaipu. Enquanto um periódico

\footnotetext{
${ }^{1}$ Artigo apresentado no Simpósio Temático (Repensar, Refletir, Interpretar e Reinterpretar a Memória, Identidade e o Patrimônio Cultural da América Latina) durante o II Seminário Latino-Americano de Estudos em Cultura - SEMLACult em Foz do Iguaçu/PR, Brasil, 2018.

${ }^{2}$ Doutoranda do Programa de Pós-graduação Interdisciplinar Sociedade, Cultura e Fronteiras da Universidade Estadual do Oeste do Paraná - UNIOESTE, na linha de Território, Memória e História; Foz do Iguaçu, Paraná; Brasil; milena.mk@gmail.com.
} 
tratou de dar voz aos atingidos e seus apoiadores, aqueles que estavam sofrendo as consequências diretas da desapropriação e das injustiças; o outro tratou a todo o momento de exaltar a obra, publicando matérias e relatando fatos e personalidades que se referiam aos aspectos positivos da construção da Usina e das suas Construtoras. Esta última posição negligenciava qualquer problemática social que a obra trazia, afora os cálculos de engenharia civil, das ferragens e da concretagem.

A pesquisa, que originou uma dissertação de mestrado $^{3}$, objetivou analisar o Boletim Poeira, criado em 1978, publicado pela Comissão Pastoral da Terra do Paraná (CPT/PR) e confrontá-lo com o discurso oficial difundido pela Itaipu Binacional também expresso no Informativo Unicon, o primeiro jornal da empresa, criado pelo Departamento de Bem-Estar Social do consórcio das empreiteiras, a UNICON, em 1978.

Através da análise das matérias apresentadas nas edições destes veículos, pretendeu-se identificar os projetos que defendiam e as práticas pedagógicas presentes nos textos, ou seja, o poder simbólico que estes periódicos construíram. O Boletim Poeira, com sua posição contrahegemônica, contestava e denunciava as ações da Itaipu, sendo o principal instrumento de comunicação que os expropriados tinham para compartilhar suas experiências, publicar concepções, denunciar as pressões sofridas pela Itaipu e a partir da sua pedagogia apresentar um projeto de ação para o movimento dos atingidos. O Informativo Unicon, como porta-voz da oficialidade, procurava fortalecer o consenso do projeto-obra da Itaipu, através de um discurso que propagava a imagem do Brasil como um país forte, um país do futuro, rico em recursos naturais e convidava os brasileiros a contribuírem para este crescimento, justificando os sacrifícios que a obra trazia em nome do progresso.

\section{Contexto Histórico}

A Usina Hidrelétrica de Itaipu fez parte de uma política nacional, organizada pela Eletrobrás Centrais Elétricas Brasileiras S/A, nas décadas de 1960, que tinha como objetivo implantar grandes projetos hidrelétricos no país, nos quais destacam-se também as Hidrelétricas de Balbina, Sobradinho e Itaparica.

O potencial elétrico do Brasil era um tema frequentemente debatido nas esferas públicas, principalmente após a crise energética instalada no final da década de 1950, provocando grandes transtornos e um pesado racionamento de energia. Desde essa época,

\footnotetext{
3 MASCARENHAS, Milena. Poeira X Unicon: confrontos e contrapontos entre expropriados e Itaipu. UNIOESTE, 2011 (Dissertação de mestrado).
} 
cogitava-se a utilização do potencial hidrelétrico do Rio Paraná, mas foi no governo de Jânio Quadros, no ano de 1961, que se iniciaram formalmente os estudos para verificar a viabilidade de uma hidrelétrica na região. Os estudos foram continuados no governo de João Goulart (1961-1964).

O Brasil vivia um período de crescimento econômico, o que significa dizer que, no futuro, haveria aumento na exigência da capacidade geradora de energia. No discurso da modernidade e do progresso propagado pelo Governo, afirmava-se ser a energia um elemento fundamental para sustentar a vida industrial e urbana de um país, atraindo novos mercados e investimentos. Todavia, há que se observar que mesmo que à custa do empobrecimento da maioria da população, pois a infraestrutura necessária é viabilizada por empréstimos externos realizados pelo governo, pagos pelos cidadãos brasileiros, que nem sempre usufruem destes investimentos.

Este período, do chamado "milagre" econômico, estendeu-se de 1969 a 1973, combinando um crescimento econômico com taxas relativamente baixas de inflação. As exportações agrícolas aumentaram e a indústria expandiu seus negócios. O governo investiu em grandes projetos, o que possibilitou a construção de estradas e hidrelétricas, viabilizadas através de empréstimos externos.

Ernesto Geisel (1974-1979), o primeiro presidente escolhido pelo Colégio Eleitoral, tomou posse em 15 de março de 1974 e seu governo está associado ao início da abertura política. No âmbito econômico, seu governo implantou o II Plano Nacional de Desenvolvimento (PND), o primeiro tinha sido lançado pelo governo Médici (1964-1974). O II PND tinha como objetivo acelerar o processo de crescimento econômico e teve como diretrizes básicas o desenvolvimento dos setores de bens de capital e insumos básicos e o fortalecimento da empresa privada nacional. Segundo Mendonça e Fontes (1991), o setor de bens de produtos duráveis deveria ser desbancado pelo de bens de produção, sendo as empresas produtivas estatais os agentes desta transformação. “O II PND, apesar de ter representado um esforço de investimento que postergou, temporariamente, os índices de recessão, tornou-se uma referência obrigatória para a segunda impulsão da dívida externa brasileira" (MENDONÇA; FONTES, 1991, p. 58).

Com a crise do petróleo iniciada no final de 1973, a questão energética assume um caráter de segurança nacional, passando a ser um assunto prioritário a ser tratado diretamente pelo Estado, em nível de gabinete da Presidência e do Conselho de Segurança Nacional (LIMA, 2006, p. 93). Todos os países importadores de petróleo foram afetados pela crise, principalmente aqueles ditos em "desenvolvimento" como o Brasil, demonstrando a 
necessidade de se obter fontes alternativas de energia. No II PND, a preocupação com os problemas energéticos ficou evidente ao propor uma redução da dependência em relação à energia externa e estudos e pesquisas de petróleo, programa nuclear, substituição parcial da gasolina pelo álcool e construção de hidrelétricas.

O Brasil, desde o final da década de 1930 e início dos anos de 1940, procurou desenvolver uma política que buscava uma aproximação com o Paraguai, consolidando-se no estabelecimento da ditadura de Stroessner.

O Tratado de Itaipu denominado Tratado para o aproveitamento hidrelétrico dos recursos hídricos do Rio Paraná, pertencentes em condomínio aos dois países, desde e inclusive o Salto Grande de Sete Quedas ou Salto de Guairá até a foz do Rio Iguaçu, foi assinado em Brasília em 26.04.1973 pelos presidentes Gen. Alfredo Stroessner, do Paraguai e Gen. Emílio Garrastazu Médici, do Brasil, entrando em vigor em 13.08.1973.

Após a formalização do Tratado entre Brasil e Paraguai, em 17 de maio de 1974, foi criada a entidade Itaipu Binacional. Criou-se no lado brasileiro um consórcio responsável pela construção da obra, denominado União de Construtoras Limitada (UNICON), formado pela Cetenco, CBPO, Camargo Correa, Andrade Guttierrez e Mendes Júnior (LIMA, 2006, p. 216). Este consórcio administrava as obras da construção da usina da Itaipu, no lado brasileiro. No lado paraguaio foi criada a CONEMPA ${ }^{4}$, composta pelas seguintes empresas: Barril Hermanos, Cia. General de Construcciones, ECCA.S.A., Ing. Civil Hermanos Baumam, ECOMIPA - Emp. Const. Min. Paraguaya e Jimeñez Gaona \& Lima. A partir disso, iniciou-se o planejamento para o início da construção da usina. Um ano depois, em 1975, foi dado início às obras.

A Barragem principal da Itaipu está $14 \mathrm{~km}$ a montante da cidade de Foz do Iguaçu e para sua construção e da Casa de Força (localizada no pé da barragem principal, transversalmente ao rio) foi necessário desviar o rio, o que foi realizado por um Canal de Desvio construído na margem esquerda. Essa foi a primeira grande meta iniciada em 1975 e concluída em 1978.

Segundo a Empresa, a construção de Itaipu foi dividida em três etapas:

A primeira abrangia a escavação do canal de desvio e a construção da estrutura de desvio, culminando com o desvio do rio do seu leito natural para o canal;

A segunda abrangia principalmente a execução das diversas estruturas de concreto, barragens de terra e enrocamento, bem como a montagem dos primeiros geradores, culminando com o fechamento do rio (e consequente

\footnotetext{
${ }^{4}$ CONEMPA designa o Consórcio das seis Empresas Construtoras Paraguaias.
} 
enchimento do reservatório) e com o início de operação da primeira unidade geradora;

A terceira compreendia a execução da casa de força no canal de desvio e a complementação da montagem das unidades geradoras restantes. (ITAIPU, 1990, p. 21)

Em 1978, foi aberto o canal de desvio do Rio Paraná, com dois quilômetros de comprimento, 150 metros de largura e 90 metros de profundidade, permitindo secar um trecho do leito original do rio para ali ser construída a barragem principal, em concreto. Com isso foi concluída uma etapa importante das obras de construção da Hidrelétrica de Itaipu, com a explosão de 55 toneladas de dinamite, conforme explica Maria de Fátima Ribeiro:

O canal de desvio das águas do Rio Paraná permaneceu aberto até 1982, quando as comportas da represa foram fechadas para segurar as águas do Paraná. O represamento formou um reservatório de água com 1.400 quilômetros quadrados, tendo a capacidade de armazenar 29 bilhões de metros cúbicos de água.

O desvio do rio permitiu a construção das obras de barragem onde, inclusive, foi construída a casa de força, que abrigou as 18 turbinas do complexo de geração de energia elétrica (RIBEIRO, 2006, p. 17).

Para a concretização da obra só no lado brasileiro a Itaipu adquiriu e/ou indenizou uma área para a formação do reservatório de 101.092,52 hectares, a maior parte era área agrícola, compreendendo 8.519 propriedades, das quais 6.913 eram rurais e 1.606 urbanas. Estima-se uma média de 40.000 moradores expropriados, somente no lado brasileiro. No lado paraguaio, onde havia uma área bem menos povoada, foi desapropriada uma área de 119.410 hectares, indenizando 1.243 propriedades, na maioria propriedades rurais, envolvendo cerca de 5.000 pessoas (ITAIPU, 2008, p. 113). As áreas desapropriadas totalizaram 3.280 hectares, na margem direita no Paraguai e 5.344 hectares, na margem esquerda no Brasil (ITAIPU, 1990, p. 19). Uma área entre Brasil e Paraguai de 1.350 quilômetros quadrados fícou submersa.

Segundo dados da empresa (ITAIPU, 2008, p. 113 - 114), no Paraguai o programa da aquisição de terras foi realizado entre os 1978 e 1982, no qual cerca de 87\% da população desapropriada se reassentou na vizinhança da região do projeto, onde puderam adquirir novas áreas em média 50\% maiores do que tinham antes. No Brasil, segundo a empresa, muitas famílias foram reassentadas em áreas de projeto de reassentamento providenciadas pelo Governo Federal, localizadas nos Estados do Paraná, Bahia e Acre. Foram reassentadas cerca de 700 famílias dando um total de 4.000 pessoas. O valor que a Empresa divulga como o total de indenização paga pela aquisição das terras foi de US\$ 190 milhões. 
Cabe registrar que, na margem direita, sobre um total de 1.324 processos de desapropriação de imóveis, iniciaram-se ações judiciais de pagamento por consignação contra apenas 28 desapropriados (cuja titularidade, de acordo com os estudos jurídicos realizados, foi considerada duvidosa) ou contra os descontentes com o montante da indenização oferecido. Isso significa que apenas $2 \%$ das propriedades foram processadas judicialmente; em suma, 98\% dos processos foram conduzidos por negociação direta.

Quadro semelhante deu-se na margem esquerda, onde, sobre um total de 8.500 processos, foram ajuizadas apenas 16 ações. As demais áreas foram adquiridas amigavelmente (ITAIPU, 1990, p. 19).

Chama a atenção na última frase: "As demais áreas foram adquiridas amigavelmente", negando todos os movimentos reivindicatórios dos expropriados que, ao longo de anos, brigaram para melhorar o valor das indenizações que recebiam por suas terras.

O Plano Diretor do canteiro industrial, bem como o planejamento geral da obra foi elaborado pelo Consórcio Enge-Rio/Logos/Gcap, definindo os níveis de produção requeridos para as diferentes frentes de serviços e dimensionando os equipamentos de apoio das instalações industriais e os de produção (ITAIPU, 1990, p. 19).

Para o desenvolvimento do projeto executivo de engenharia da usina foram contratadas quatro empresas brasileiras associadas ao Grupo Consultor Alto Paraná (Gcap): a Engevix Engenharia S.A., do Rio de Janeiro, responsável pela elaboração do projeto final do vertedouro e da barragem lateral direita; a Promon Engenharia Ltda., de São Paulo, tinha como tarefa a elaboração do projeto final da barragem principal; a Themag Engenharia Ltda., de São Paulo, responsável pela elaboração do projeto final da casa de força; e a Hidroservice Engenharia Ltda., também de São Paulo, responsável pela elaboração do projeto das barragens de terra (ITAIPU, 1990, p. 19).

A Itaipu Binacional contratou o consórcio constituído pela empresa americana International Engineering Company Inc. (Ieco), de São Francisco, e pela empresa italiana Eletroconsult SpA (Elc), de Milão, para coordenar os trabalhos realizados pelas empresas citadas acima, além de executar alguns trabalhos específicos de engenharia, como o projeto das obras de desvio, barragem de enrocamento, especificação para turbinas e geradores e equipamentos de extra-alta-tensão (ITAIPU, 1990, p. 19).

Um dos setores mais beneficiados com a construção de Itaipu foram as empreiteiras, destacando-se: a Cetenco $^{5}$ que atua no Brasil e no exterior desde 1930; a Companhia Brasileira de Projetos e Obras (CBPO), atualmente faz parte do grupo Odebrecht e

\footnotetext{
${ }^{5}$ Disponível em: <www.cetenco.com.br> Acesso em janeiro de 2010.
} 
inicialmente foi de propriedade de Oscar Americano; Camargo Correa ${ }^{6}$, empresa paulista fundada em 1939; Andrade Guttierrez , empresa mineira fundada em 1948; e Mendes Júnior, também mineira fundada em 1953. Esta última era considerada a maior construtora do país e durante a construção da Usina de Itaipu, segundo Tão Gomes Pinto (2009), foi a responsável por $89 \%$ da obra, somando às demais empreiteiras os $11 \%$ restantes.

As cinco empreiteiras citadas formaram a UNICON e constituíam o Consórcio Brasileiro-Paraguaio UNICON/CONEMPA e eram responsáveis por se encarregar de executar as obras civis, de acordo com os contratos firmados e assinados em 06 de outubro de 1975 e em 17 de maio de 1977. A CONEMPA era formada pelas firmas paraguaias Barril Hermanos, Cia. General de Construcciones (Ecca S.A.), a Empresa Construtora Minera Paraguaya S.A. (Ecomipa), e a Civil Hermann Baumann e Jimenez Gaona \& Lima.

Ao todo foram 15 municípios atingidos pela barragem, tendo que lidar com o processo de desapropriação das terras atingidas pelo lago de Itaipu. No livro Itaipu: as faces de um mega projeto de desenvolvimento, há uma citação do José de Souza Martins que retrata a lógica da Empresa: "a expropriação constitui uma característica essencial do processo de crescimento do capitalismo" (MARTINS, 1991, apud, LIMA, 2006, p. 333), sendo necessária a implantação dos objetivos para que o capital se estabeleça. Esse foi o grande argumento utilizado pelas autoridades para legitimar as ações expropriatórias.

\section{Sobre o Poeira}

Para fortalecer a articulação e a formação política da base social da CPT/PR no Oeste e Sudoeste do Paraná, em 1978, a Comissão passou a produzir um boletim informativo bimensal, o Poeira, produzido inicialmente em Marechal Cândido Rondon, com o objetivo de informar, também as CEBs, sobre as ações da CPT/PR e os problemas enfrentados pelos agricultores dessas regiões. Este nome foi sugerido por Kirinus que, em uma entrevista concedida a Frank Antonio Mezzomo, explicou sua origem:

(...) pela poeira os agricultores identificavam os solos mais férteis. Terra arenosa não levanta poeira. Parece um paradoxo, mas a sabedoria popular ensinava de que quanto mais solta a terra, mais levanta poeira e mais liga tem, portanto é sinônimo de terra fértil.

Por outro lado, uma das prevenções de quem anda pelas estradas rurais com curvas fechadas, pois elas normalmente acompanhavam as divisas das colônias recém abertas, era de poder observar pela poeira que levantam os carros. Metaforicamente o nome poeira lembrava o movimento e o objetivo da CPT era acompanhar os

\footnotetext{
${ }^{6}$ Disponível em: <www.camargocorrea.com.br> Acesso em janeiro de 2010.

${ }^{7}$ Disponível em: <www.andradegutierrez.com.br> Acesso em janeiro de 2010.

${ }^{8}$ Disponível em: <www.mendesjunior.com.br> Acesso em janeiro de 2010.
} 
movimentos e a poeira levantada pelas CEBs. Seria mais ou menos uma semelhança ao ditado popular que diz onde há fumaça, há fogo (MEZZOMO, 2009, p. 40).

O primeiro número do Boletim Poeira foi publicado em março de 1978 e iniciou com uma tiragem de 120 unidades. A capa do informativo era produzida manualmente desde o nome do Boletim até os desenhos ou charges. A parte interna era escrita com máquina de escrever na matriz e depois de pronto era reproduzido num mimeógrafo à tinta e distribuído gratuitamente. $\mathrm{O}$ boletim era impresso em papel sulfite tamanho ofício, por vezes frente e outras, frente e verso. A periodicidade, em geral, ocorria bimensalmente, porém há alguns números sequenciais que ficaram quase sete meses sem ter publicação, a exemplo do número 9 que foi publicado em maio de 1979 e o número 10 somente em dezembro do mesmo ano, período que coincidiu com a transferência da sede da CPT de Rondon para Curitiba.

As charges permeiam o conteúdo do Boletim Poeira e aparecem sempre com o sentido de fazer uma crítica humorística de um fato ou acontecimento específico e em geral estão relacionadas com a natureza política da atuação dos sujeitos representados. As charges podem conter muitas informações, a exemplo do primeiro número do Poeira, que tinha na capa a imagem de um agricultor caracterizado pelo chapéu e olhando para as mãos vazias e abertas, demonstrando que não tinha ferramenta para trabalhar nem terra para plantar ou criar animais. Em torno do colono foram indicados os principais problemas que enfrentava: 


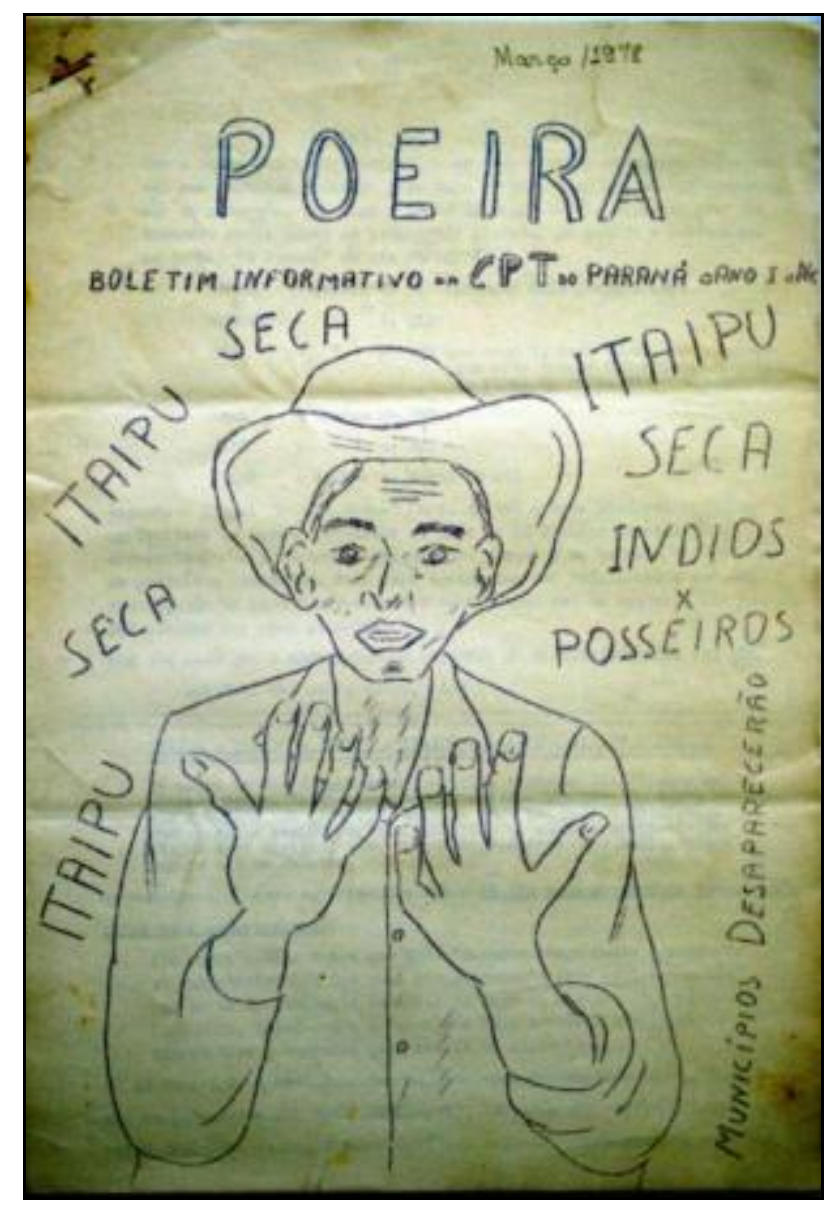

Figura - Capa do Boletim Poeira no. 1.

Fonte: BP, Ano I, no. 1, março/1978, p. 1.

O primeiro número do Boletim Poeira, conforme observamos na capa acima tratou de um dos maiores problemas neste período para os agricultores que viviam às margens do Rio Paraná, que era a construção da Itaipu, sendo que neste ano de 1978 iniciaram a construção da barragem principal (LIMA, 2006, p. 219) e teve início o programa de desapropriação aumentando a pressão da Empresa para os que ainda não tinham negociado suas terras.

O informativo tinha como objetivo central denunciar os problemas que atingiam os agricultores, a temática da luta pela terra era a principal preocupação da CPT, permeando em todos os números do boletim.

\section{Sobre o Informativo Unicon: o/no lugar do concreto e do ferro}

Este item traz um resumo da análise do material produzido pela Itaipu/UNICON, através do Departamento de Bem-Estar Social, para compreender como foi construído o 
discurso pró-Itaipu. Percebe-se, ao analisar os dois principais materiais dessa pesquisa, que se trata de duas "Itaipus": - uma descrita no Boletim Poeira expropriadora e injusta; - a outra descrita no Informativo Unicon como uma das maravilhas do mundo moderno, exemplo de grandiosidade, imponência e salvadora de um país em "desenvolvimento".

A usina foi planejada para atender a necessidade de energia, principalmente do setor urbano-industrial e de serviços instalados no Sudeste brasileiro. Estrategicamente visava garantir a infraestrutura de energia para o processo de recuperação da crise de 1973 no setor produtivo, fortalecendo a base empresarial no desenvolvimento do capitalismo no Brasil e a hegemonia das classes dominantes. Por outro lado, o fenômeno da urbanização e a ampliação dos bens eletrodomésticos no consumo da população urbana e rural requeria que o setor de geração, transmissão e distribuição de energia para o consumo industrial/comercial, residencial e público.

Para justificar tamanha obra, ou melhor, o tamanho da obra, era necessário produzir um discurso para atingir o conjunto da população, dos setores econômico-sociais e de instituições e convencê-los. Por outro lado, no núcleo estratégico da fronteira, além dos meios de convencimento, também foram utilizados recursos e aparatos de repressão e intimidação.

O discurso pró-Itaipu era fundamental para convencer e estabelecer o consenso necessário na população, principalmente àqueles que estavam mais próximos e dentro dos limites da obra, que seriam direta ou indiretamente afetados pela usina. Desta forma, associavam "os sacrifícios" ao valor do patriotismo, convidando os brasileiros que seriam atingidos e os barrageiros (operários da construção civil) a contribuírem e serem partícipes deste crescimento e do espetáculo: a construção da maior hidrelétrica do mundo. Várias foram as formas e meios utilizados para difundir este discurso: panfletos, jingles, cartazes, filmes, empregos, favorecimentos, mordomias, apadrinhamentos, especulação, corrupção etc. Uma série de recursos de mídia (escrita e falada) foi utilizada para justificar esse projeto estratégico, dito "nacional".

Após a assinatura do Tratado de Itaipu, em 1973, criou-se no lado brasileiro um consórcio responsável pela construção da obra, denominado União de Construtoras Limitada (UNICON). O Informativo Unicon foi criado no dia 4 de fevereiro de 1978, por um órgão do Departamento de Bem-Estar Social da UNICON. Era bilíngue, português e espanhol, respectivamente para cada lado, e com periodicidade quinzenal, formato de tabloide e com uma tiragem que variou entre 9.000 a 20.000 exemplares. $O$ objetivo, segundo o Consórcio/Itaipu, era divulgar os acontecimentos em todos os níveis de atuação da Itaipu, do ponto de vista deste bloco (Itaipu, governos militares e consórcio no Brasil e no Paraguai). 
O informativo conta com uma série de notícias que incluem dados gerais sobre a obra, histórias de barrageiros, apologia à obra e ao consórcio UNICON, informações de utilidade pública (saúde, segurança), entretenimento, esportes, serviços, divulgação de cursos, classificados, notícias sobre os bairros administrados pela Itaipu etc.

Chama a atenção à quantidade de entretenimento oferecido pela Empresa, aos funcionários da Itaipu e familiares, que vai desde lutas de boxe, shows, programação de festas, jantares de confraternização, excursões, concursos e muito esporte, principalmente o futebol. Numa das reportagens, a matéria comenta: "o objetivo é proporcionar a esta gente momentos de sadia descontração, para canalizar as energias num sentido educativo" (UNICON. Ano I, no. 01, Fevereiro, 1978, p. 05).

No caso da empresa/consórcio - Itaipu/UNICON - a maior preocupação era com a disciplina e a homogeneização de interesses dos funcionários da Itaipu, citadas inúmeras vezes no informativo. No primeiro editorial encontramos as seguintes frases que traduzem o objetivo do periódico: "para alcançar objetivos comuns", o periódico vem a ser "mais um elemento de integração" e por fim, "integração de todos os funcionários".

O que se percebe ao ler o Informativo Unicon é a total ausência de conflitos na Itaipu. O informativo retratava a perfeição da obra, da engenharia, do trabalho e suor dos homens que nela trabalhavam e na união "harmônica" de dois povos "irmãos". Logicamente não encontramos na pesquisa um diálogo direto entre o Unicon e o Poeira, enquanto se percebe inúmeras tentativas do Poeira estabelecer um diálogo com a Itaipu, o contrário não era o mesmo. Primeiro porque o Informativo Unicon estava comprometido, tanto financeiramente quanto ideologicamente com um determinado projeto, segundo porque cada qual defendia um projeto e uma causa.

\section{Conclusões}

Neste artigo foram analisados dois periódicos produzidos por sujeitos que participaram de diferentes maneiras do processo que envolveu a construção da usina de Itaipu. O Boletim Poeira e o Informativo Unicon foram pesquisados com o objetivo de expor as contradições deste empreendimento construído com base em muitos conflitos. Os dois instrumentos de organização foram pensados não só para noticiar o que acontecia, mas também educar e organizar seus leitores diante da construção da hidrelétrica binacional.

Houve muita resistência por parte dos expropriados, conforme analisado no trabalho. Muitos deles tiveram que sair de suas terras sem uma indenização justa. Diante da constatação do embuste do "preço justo", os expropriados criaram, principalmente através da atuação da 
Comissão Pastoral da Terra e das Comunidades Eclesiais de Base, um movimento social de resistência e reivindicação que incluiu a produção de materiais de formação e comunicação, a exemplo do O Mausoléu do Faraó, o Boletim Poeira e A Taipa da Injustiça, nos quais socializavam as ações, propuseram formas de organização e de discussões e denunciavam as injustiças que sabiam que a direção da Itaipu realizava.

Por outro lado, as empresas do consórcio UNICON, criaram o Informativo Unicon, voltado principalmente para os barrageiros, no qual se constatou não se tratar de um veículo de comunicação que dialogava com os expropriados, pelo contrário, na pesquisa realizada fica evidente o total silenciamento com as causas do Movimento Justiça e Terra, retratando em suas páginas a "magnitude" da obra, as inúmeras atividades oferecidas para os funcionários, as festas comemorativas e biografias dos engenheiros responsáveis pela obra, descartando qualquer menção aos agricultores, índios, posseiros e arrendatários que tiveram que obrigatoriamente sair de suas casas para viabilizar esse "megaprojeto".

De um lado, vimos as constantes lutas empreendidas pelos expropriados que lutavam por justiça nas indenizações (terras, estabelecimentos, benfeitorias, investimentos em infraestrutura e lucros cessantes etc.); do outro, o bloco Itaipu Binacional tinha seus interesses e se articulava com várias estratégias para ludibriar o movimento. As diferenças tinham caráter de confrontos (práticas de efetivação dos projetos e resistências) e de contrapontos (construção de legalidade e/ou legitimidade dos projetos) que foram tecidos nas lutas sociais realizadas, principalmente no período da construção da barragem.

\section{Fontes}

INFORMATIVO UNICON $\mathrm{N}^{\circ}$ 1. Cascavel: 4 de fevereiro de 1978 a $\mathrm{n}^{\circ} 117$. Cascavel: dezembro de 1985.

CPT BOLETIM POEIRA. Março de 1978 a janeiro de 1986.

\section{Referências}

BOURDIEU, Pierre. O poder simbólico. Rio de Janeiro: Berttand Brasil, 2007.

CATTA, Luiz Eduardo Pena. O Cotidiano de uma fronteira: a perversidade da modernidade. Cascavel: Edunioeste, 2002.

COMISSÃO PASTORAL DA TERRA. CPT: Pastoral e Compromisso. Petrópolis: Vozes, 1983.

FERES, João Bosco. Propriedade da Terra: opressão e miséria: o meio rural na história social do Brasil. Amsterdam: CEDLA, 1990. 
GERMANI, Guiomar Inez. Expropriados terra e água: o conflito de Itaipu. Salvador: Edufba: ULBRA, 2003.

ITAIPU Binacional (Brasil). Diretoria Jurídica. Natureza Jurídica da Itaipu. Curitiba: Itaipu Binacional, 2004.

KIRINUS, Gernote. Entre a cruz e a política. Beija-flor. [1979?]

LIMA, Perci. Foz do Iguaçu e sua história. Foz do Iguaçu, PR, 2001.

LIMA, Ivone Teresinha Carletto de. Itaipu: as faces de um megaprojeto de desenvolvimento. Niterói: Germânica, 2006.

MASCARENHAS, Milena. Poeira X Unicon: confrontos e contrapontos entre expropriados e Itaipu. UNIOESTE, 2011. (Dissertação de mestrado)

Idem. Poeira: a expressão dos atingidos de Itaipu. In: Silva, M.; Koling, P. (Org.). Terra e Poder: Abordagens em História Agrária. Porto Alegre: FCM Editora, 2015. P. 121-140.

MAZZAROLLO, Juvêncio. A Taipa da injustiça: esbanjamento econômico, drama social e holocausto ecológico em Itaipu. São Paulo: Loyola, 2003.

MENDONÇA, Sonia. R. de; FONTES, V. M. História do Brasil Recente: 1964-1980. 2a. ed. São Paulo: Ática, 1991.

MEZZOMO, Frank Antonio. Memória dos movimentos sociais no Oeste do Paraná: Gernote Kirinus, Adriano Van de Vem, Werner Fuchs. Campo Mourão: FECILCAM, 2009.

PINTO, Tão Gomes. Itaipu: Integração em concreto ou uma pedra no caminho?. São Paulo: Manole, 2009.

PEREIRA, Osny Duarte. Itaipu - prós e contras. Rio de Janeiro: Paz e Terra, 1974.

RIBEIRO, Maria de Fátima Bento. Itaipu, a dança das águas: histórias e memórias de 1966 a 1984. Campinas: Universidade Estadual de Campinas, 2006. 260 f. Tese (doutorado), Departamento de História do Instituto de Filosofia e Ciências Humanas, Campinas, 2006.

. Memórias do concreto: vozes na construção de Itaipu. Cascavel: Edunioeste, 2002.

SCHILLING, Paulo R., CANESE, Ricardo. Itaipu - geopolítica e corrupção. São Paulo: CEDI, 1991.

SCHMITT, Judith Veranisa. Os atingidos por Itaipu: História e memória. Oeste do Paraná, décadas de 1970 a 2000. Marechal Cândido Rondon, 2008. 130 f. Dissertação (Mestrado), Programa de Pós-Graduação Stricto Sensu em História, Marechal Cândido Rondon, 2008. 